\title{
Coupling sulfur isotopes with lipid biomarkers at Europa-analogue hypersaline springs in the Arctic
}

\author{
AROLA MORERAS-MARTI ${ }^{1}$, MARK G FOX-POWELL ${ }^{2}$, \\ CLAIRE COUSINS $^{3}$, JAIME TONEY ${ }^{4}$ AND AUBREY \\ ZERKLE $^{3}$ \\ ${ }^{1}$ School of Earth and Environmental Sciences, St Andrews \\ University \\ ${ }^{2}$ Open University \\ ${ }^{3}$ University of St Andrews \\ ${ }^{4}$ University of Glasgow \\ Presenting Author: amm48@st-andrews.ac.uk
}

Axel Heiberg Island (AHI) in the Canadian Arctic, hosts unique hypersaline springs ( $>10$ wt. \%) with subzero temperatures $\left(-5\right.$ to $\left.8{ }^{\circ} \mathrm{C}\right)$ that present hydrated $\mathrm{Na}_{2} \mathrm{SO}_{4}$ and $\mathrm{Cl}$ salts as predominant phases $[1,2]$. These springs are analogues for brines within Jupiter's icy moon Europa, as there is evidence of hydrated compounds on Europa's surface proposed to be salts such as $\mathrm{Na}_{2} \mathrm{SO}_{4}$ minerals delivered from subsurface liquid reservoirs $[2,3]$.

We sampled two springs with different brine characteristics and salt mineralogy: Lost Hammer spring and Colour Peak spring. Lost Hammer spring is formed by a salt apron and outflow stream, with salt crystals dominating the sediment. From the spring vent itself to the distal outflow channel, the brine $\mathrm{pH}$ ranges from 5.7 to 6 , temperature increases from -3.6 to $1.8{ }^{\circ} \mathrm{C}$ and dissolved oxygen increases from 0.1 to $7.7 \mathrm{ppm}$ [2]. The water sulfate concentrations vary between 5931 and $6130 \mathrm{ppm}$ [2]. Colour Peak spring waters are warmer $\left(3.4\right.$ to $\left.8.4{ }^{\circ} \mathrm{C}\right)$, $\mathrm{pH}$ ranges from 6.98 to 7.75 and dissolved oxygen from 0.4 to 6.98 $\mathrm{ppm}$. Sulfate concentrations vary beween 2292 and $2391 \mathrm{ppm}$.

We investigated the $\mathrm{S}$ isotope values together with lipid biomarkers (PAHs, hopanes and diols) from the salt deposits of these streams. These data have been combined to investigate how both organic and isotopic biosignatures are captured and preserved in natural systems relevant to Europa's surface. The upcoming mission Europa Clipper and the proposed Europa Lander will be able to analyse organic molecules and potentially sulfur isotopes. The results from this study will inform the development of these missions by understanding the preservation of of lipid biomarkers and isotopic biosignatures in materials with similar mineralogy to Europa's surface.

[1] Ward, M. K. \& Pollard, W. H. (2018) EPSL, 504, 126-138. [2] Fox-Powell, M. G. et al. (2019) GRL 46, 5759-5767. [3] Battler, M. M. et al. (2013) Icarus, 224, 364-381. 